\title{
Osteo-Meningeal Breaches in Benin
}

Lawson Afouda Sonia $^{1^{*}}$, Hans Houinsou Isaac ${ }^{2}$, Avakoudjo François $^{1}$, Adjien Constant ${ }^{3}$, Gnonlonfoun Dieudonné ${ }^{3}$, Doussoh Marcos ${ }^{1}$ and Adjibabi Wassi $^{1}$

${ }^{1}$ Ear Nose Throat department of Hubert Koutoukou Maga National Teaching Hospital of Cotonou, Benin

${ }^{2}$ Neurosurgery department of Hubert Koutoukou Maga National Teaching Hospital of Cotonou, Benin

${ }^{3}$ Neurology department of Hubert Koutoukou Maga National Teaching Hospital of Cotonou, Benin

*Corresponding author: Lawson Afouda Sonia, Ear Nose Throat department of Hubert Koutoukou Maga National Teaching Hospital of Cotonou, Benin, Tel: 00(229) 97 68 82 37; E-mail: olatundeother@yahoo.fr

Received date: July 07, 2015; Accepted date: August 12, 2015; Published date: August 17, 2015

Copyright: $@ 2015$ Sonia LA et al. This is an open-access article distributed under the terms of the Creative Commons Attribution License, which permits unrestricted use, distribution, and reproduction in any medium, provided the original author and source are credited.

\begin{abstract}
Introduction: To describe epidemiology of osteo-meningeal breaches and to determine diagnosis and therapeutic aspects.

Method: Retrospective study from January 1, 2001 to December 31, 2009 on patients who presented a rhinoliquorrhea or otoliquorrhea at Ear Nose Throat and neurosurgery departments of Hubert Koutoukou Maga National Teaching Hospital of Cotonou.

Results: Twenty-three patients were identified among whom 3 inflammatory and 20 post traumatic that included a surgery on 1 case of right ethmoido-frontal mucocel. The sex ratio was $19 / 4$ and average age 37.48 years, with age range from 22 to 61 . Thirteen patients underwent TDM which showed a defect: ethmoidal (6), frontal (1), frontoethmoidal (2), sphenoidal (3), temporal (1).Prophylactic antibiotic therapy and medical monitoring practiced by patients associated to surgery (6): levying of frontal sinking (3), plastic surgery by abdominal grease (3) with a case of meningocele resection. Follow up period marked by spontaneous depletion (14), post- surgery resolution (5), persistence of liquorrhea after surgery (1), death without depletion out of surgery (2), leaving against medical notice in spite of persistence of liquorrhea (1)
\end{abstract}

Conclusion: Cranial skull traumatisms dominate the causes of osteo meningeal breaches. Theirs manifestations were liquorrhea. The medical imagery is primordial in diagnosis and the treatment medical is associated to surgery.

Keywords: Osteo meningeal breaches; Traumatism-inflammation; Liquorrhea

\section{Introduction}

The osteo- meningeal breach is an osteo-meningeal solution where the cerebrospinal fluid flows into a cavity of aeric skull base $[1,2]$. Its impact is difficult to assess because of its self-limiting nature. Whatever the aetio-pathogenesis, the osteo-meningeal lesion first clinical symptom is rhino-liquorrhea or oto-liquorrhea according to the seat of continuity. Its diagnosis requires the achievement of a high computed tomography resolution or a magnetic imaging resonance, associated with specific biological tests of flow $[1,3]$. The risk of infectious complications or mechanical type of meningitis or meningo-encephalocele reflects how the osteo-meningeal breaches are serious and the adequate medical and sometimes surgical treatment.

The objective of the study conducted at the National Teaching Hospital of Cotonou, Benin was to describe the etiological and epidemiological aspects of osteo-meningeal breaches and to determine the diagnostic and therapeutic approach.

\section{Method}

It was a retrospective study conducted at Ear Nose Throat and Neurosurgery departments of Hubert Koutoukou Maga National Teaching Hospital of Cotonou, Benin, from the January 1, 2001 to
December 31, 2009. It was based on descriptive analysis of medical record.

The study took into account patients with nasal or ear cerebrospinal fluid discharge. We systematically looked for rounded sign when the liquid was stained with blood; it appears through concentric lipped less red from inside to outside according to the molecular weight of blood and cerebrospinal fluid. The anamnestic and clinical context indicates an impact of the base of the skull which required a CT scan. In some cases, the standard radiographs indicated the fracture lines of the extended canopy at the extended base of the skull.

All the patients were hospitalized and underwent empirical antibiotic therapy that inclined the meningeal barrier including $B$ lactams and derivatives, and macrolides or quinolones depending on the extent of the break-bone and mucosa. The association between certain molecules was possible based on the profusion and duration of the flow. The surgical treatment was in the absence of depletion after two months. It consisted of the removal of front depressed fracture of the skull associated with the laying of autologous iliac graft or clogging of the gap with abdominal fat or Surgicel ${ }^{\circ}$ depending on the importance of osteo-meningeal defect.

Patients with a confirmed serous and inflammatory rhinorrhea of sinonasal origin without flow of CSF or serous otorrhea in a nontraumatic context and without tympanic perforation were not included in this study. The cytobacteriological examination of the CSF 
Citation: Sonia LA, Isaac HH, François A, Constant A, Dieudonné G, et al. (2015) Osteo-Meningeal Breaches in Benin. J Neurol Neurophysiol 6:

Page 2 of 4

was performed in patients with hyperthermia. Thus, the number of microL neutrophils higher than $2000 / \mu \mathrm{L}$, the results of total protein concentration and the glucose level whose values successively exceeding $100 \mathrm{mg} / \mathrm{dL}$ and less than $40 \mathrm{mg} / \mathrm{dL}$ confirmed the diagnosis of meningitis upon osteo-meningitis breaches.

The outcome was assessed on the depletion of the liquorrhea, the temperature monitoring and signs of intracranial hypertension. Clinical monitoring was conducted on the 8th, 30th, 90th, 180th day after the patient release at 1 year.

The studied variables were epidemiological (frequency, age, gender); diagnostic (clinical, CT); therapeutic (medical, surgical); scalable (liquorrhea depletion). Data were analyzed using the EPIINFO version 6 .

\section{Results}

23 cases of osteo-meningeal breaches were identified after 10 years including 3 inflammatory, 20 traumatic (86.95\%) and 1 iatrogenic cases, or 2.3 cases per year. The most affected age group was ranged between 30 to 49 years. The average age was 37.48 years with extremes of 22 and 61 years. A male predominance was observed with a sex ratio of $19 / 4$ or 4.75 .

The key complaint was a rhinoliquorrhea $(15 / 23)$ or otoliquorrhea $(8 / 23)$. The associated functional signs have been summarized in Table 1.

\begin{tabular}{|l|l|}
\hline & Number \\
\hline Headaches & 20 \\
\hline Loss of consciousness & 14 \\
\hline Insomnia & 12 \\
\hline Dizziness & 11 \\
\hline Loss of hearing & 09 \\
\hline Nasal obstruction & 08 \\
\hline Epistaxis & 06 \\
\hline Otorragy & 06 \\
\hline Otalgy (earache) & 06 \\
\hline
\end{tabular}

Table 1: Distribution of patients according to functional signs associated with liquorrhea.

The average time of consultation was 2.35 days with a range of 2 hours to 45 days in cases of post traumatic osteo-meningeal breaches. In osteo-meningeal inflammatory breaches, the rhinoliquorrhea appeared as a result of chronic rhinosinusitis that has lasted for 6-10 years. In traumatic cases the average time to onset was 1.9 days with extremes of 3 hours and 16 days.

Traumatic osteo-meningeal breaches (16/20) resulted mostly from road accidents of which 15 helmetless motorcyclists.

A history of former head trauma (1 case) and chronic sinusitis (4 cases) associated with morbid obesity (1 case) and aethmoido-frontal mucocele (1 case) were reported.

Physical examination highlights the signs shown in Table 2.

\begin{tabular}{|l|l|}
\hline & Number \\
\hline $\begin{array}{l}\text { Rhinologic signs Rhinoliquorrhea } \\
\text { Epistaxis }\end{array}$ & 15 \\
\hline Otologic signs Otoliquorrhea & 5 \\
Tympanic Perforation & 8 \\
Otorragy & 8 \\
\hline Neurological signs Convulsions & 4 \\
Stage II, III, VII & 1 \\
\hline Bone breaches *skull fracture & 5 \\
General signs Hyperthermia & 3 \\
Other lesions mucocutaneous & 2 \\
\hline
\end{tabular}

Table 2: Distribution of patients according to physical examination results. occipito-parietal, frontal and midface bone breaches.

CT was performed on 13 patients and allowed to objectify the locations of the bone breaches summarized in Table 3.Other CT lesions were a pneumo-cephalus ( 3 cases) (Figure 1), front mucocele with osteo brain breaches (Figure 2) and a meningocele (1 case). Plain radiography of the skull practiced only in 4 cases objectified radiolucent linear breaches or fracture or radiopaque parietal or temporal region craniofacial polyfracture, a fracture of the orbital floor, of frontal breaches or depressed skull fracture, opacity mastoid air cells. Associations of lesions were also noted.

\begin{tabular}{|l|l|}
\hline & Number \\
\hline Ethmoid & 6 \\
\hline Sphenoid & 3 \\
\hline $\begin{array}{l}\text { Fronto-ethmoidal } \\
\text { frontal }\end{array}$ & 2 \\
\hline temporal & 1 \\
\hline TOTAL & 1 \\
\hline
\end{tabular}

Table 3: Distribution of the location of fracture breaches according to TDM. 


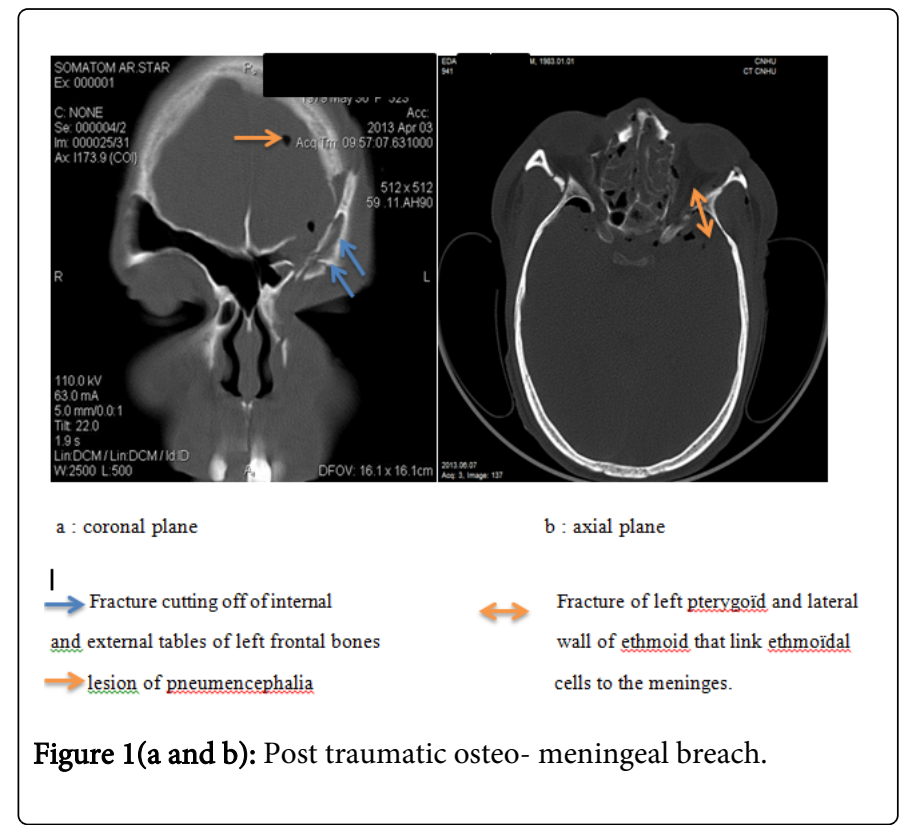

The treatment consisted of life style and dietary and postural measures, symptomatic medical treatment associated with surgical treatment in 6 cases. The Medical treatment was summarized in Table 4. In 3 traumatic cases, an external lifting of a depressed skull fracture was needed with an iliac laying graft $(2$ cases) and Surgicel. In inflammatory cases, it was carried out with a sealing of abdominal fat and biological glue maintained by a silastic blade ( 3 cases) in 1 case with a prior resection of the meningocele.

\begin{tabular}{|l|l|}
\hline & Patients \\
\hline $\begin{array}{l}\text { Antibiotics B lactam } \\
\text { Quinolones } \\
\text { *Aminosides }\end{array}$ & 23 \\
\hline $\begin{array}{l}\text { Pain killers Paracetamol+/- Codeine } \\
\text { Tramadol }\end{array}$ & \\
\hline Anti-inflammatories AIS /NSAI & 18 \\
\hline Benzodiazepines & 13 \\
\hline $\begin{array}{l}\text { Vasodilatators } \\
\text { Antihistamines }\end{array}$ & 06 \\
\hline Laxatives & 10 \\
\hline
\end{tabular}

Table 4: Distribution of patients according to the medicinal treatment. *Aminoglycosides have sometimes been associated with one of the three above mentioned antibiotics.

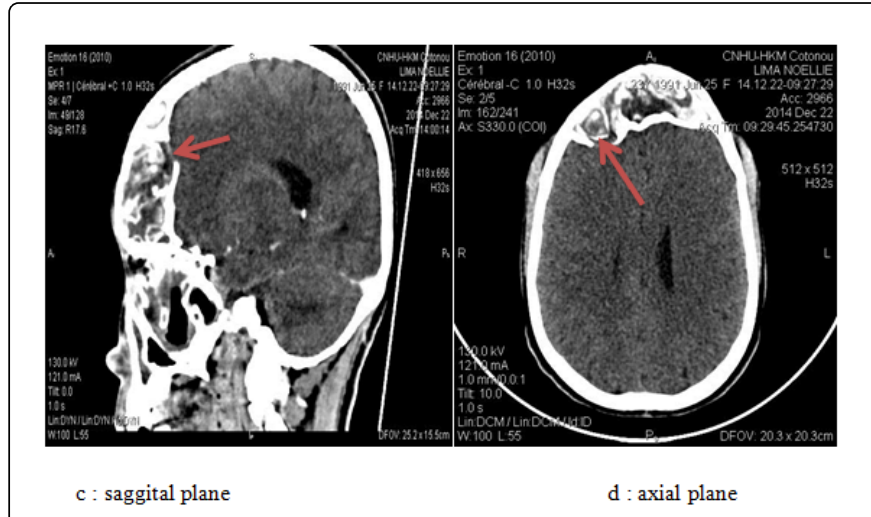

Figure 2: (c and d) inflammatory osteo-meningeal breach. Frontal Mucocele after sinus surgery for naso-sinusal aspergillosis.

The evolution was marked by spontaneous depletion within an average of 6 days and a post-surgical resolution in 5 cases. A persistence of flow was observed in 3 patients; in 1 case despite surgery and in 2 cases followed by death without any surgery in an array of meningitis and intracranial hypertension. A discharge against medical advice despite the persistence of liquorrhea was recorded in 1 case.

\section{Discussion}

The osteo-meningeal breach is a common disease of multiple aetiology. Its incidence has varied from 4.6 to 7.6 cases per year in the United States in 2004 and 9 cases per year in Belgium in 2008 [4-6]. It was an average of 2.3 cases per year in our series and affected young adults with average age of 37.48 years while Bell and al [4,5] reported an average age ranging from 28 to 49 years with a male predominance.

The rhino-liquorrheas can be primary or secondary, $96 \%$ in the latter case by Schlosser [7]. Traumas have been concerned in their genesis, and 10\% iatrogenic causes were found [7-9]. In our study 20 out of 23 cases $(86.95 \%)$ of secondary causes were attributed mainly to trauma. These were related to motorbites accidents involving riders not respecting highway code such as helmet wearing. In 2004 in the United States of America, Eljamel found 63\% of rhino-liquorrhea traumatic[9]. Traumatic causes may be related to surgery of the skull base at a rate varying between $42 \%$ and $66.66 \%[5,10]$.

They can also occur in a tumor sino-nasal cavity [11]. In our study, it was an osteo-meningeal surgery after a breach of the ethmoidofrontal mucocele occurred on rhino-sinusitis with mucormycosis. Primary rhinorrhea may be related to a deformity of the anterior and middle floor of the skull basis, also related to inflammatory causes or erosive breaches linked to an arachnoid cyst [1].

The otoliquorrhea are less frequent but often traumatic related [11]. They accounted for 8 out of 23 cases and were essentially the result of highway accident in our study.

The anamnestic liquorrhea in its context was the main symptom of osteoarthritis meningeal lesion. The sign of the desired roundel from any bloody atrial or nasal flow allowed to make the difference between the presence of pure blood and spinal fluid. When the flow was nonexistent or scarce, Dandy's method, head bent forward and down has been helpful in triggering or accentuating it. In this study, the liquorrhea was associated with an initial loss of consciousness, headache, dizziness and hearing loss. For Tabaouti, osteo-meningeal 
breach is suspected in any uni or bilateral flow from the nasal or external auditory meatus; associated signs such as headache or dysosmia can be indicators of the presence of complications such as meningitis, brain abscess or osteomyelitis of the skull basis [1].

The CT high resolution and MRI are of great use for localization and assessment of damage, contributing to the surgery guidance when necessary to avoid invalid explorations. Isotopic cisternography during outflow is more invasive and is realized after intranasal injection of fluorescein [1-3]. These explorations were performed and allowed to locate ethmoid and / or sphenoid breaches [5, 12-14]. Only the scanner was used in our diagnostic approach.

The biochemical analysis of the cerebrospinal fluid is essential in cases of light or intermittent flow and when the high-resolution scanner was not contributory [2, 15]. Conventional biochemical analyses of protein or glucose in the flow may indicate the presence of cerebrospinal fluid. But they require a large sample and have the disadvantage of being disabled in the event of blood contamination. Similarly, the determination of glucose test strips in bedside secretions has low sensitivity and specificity but can be useful in emergencies when it is framed by the transferrin $\beta 2$ and $\beta$ - protein trace [1]. None of these biological tests could be performed in our context.

The therapeutic management of osteo-meningeal breach must consider the cause, anatomic site, the size of the defect, the age of the patient and pressure intra cranial underlying. This care associates the rest of the patient and antibiotic prophylaxis to reduce the risk of developing meningitis $[8,16]$.

Surgery is the second part of the treatment. It consists of lumbar punctures-drainages that promote spontaneous healing. But in case the flow persists or post-traumatic multiple breaches, a clogging of the site is performed with a bone graft, temporalis fascia or abdominal fat. If unsuccessful, a ventriculo-peritoneal shunt or ventricular-atrial cerebrospinal fluid is produced. It is indicated in persistent spontaneous fistulas, in large bone crash, or in the presence of a concomitant high pressure hydrocephalus [7,17]. The endo-nasal endoscopic classic is the most currently practiced because of the aesthetic benefit and conclusive results in the management of osteomeningeal breach of the prior floor of the skull basis as evidenced by several authors $[6,12,18]$. The scarcest neurosurgery channel is indicated in case of severe defect. [5] Only 3 patients were treated with endonasal endoscopic and 3 other externally in our study.

The resolution of the flow is often common in 2 to 10 days with spontaneous healing in 80 to $95 \%$ of the cases [1]. Recurrence or persistence of the treated flow with endoscopic surgery experienced an amendment rate of $90 \%$ to $100 \%[12 ; 18]$. Similar results were found in this study where the identified recidivism factor was morbid obesity in a patient. The occurrence of intracranial hypertension and meningitis were the two noted causes of death.

\section{Conclusion}

The causes of osteo-meningeal breaches are dominated by the trauma of the skull basis, rarely affected by sinus inflammation. They are manifested by rhinoliquorrhea or otoliquorrhea. Their care is a symptomatic medical treatment associated with a need for surgery.
The spontaneous self-limiting evolution may be complicated by meningitis or intracranial hypertension worsening the prognosis. A better outreach campaign on road safety is likely to reduce the risk of injury as a result of highway accident and therefore liquorrhea.

\section{References}

1. Tabaouti K, Kraoul L, Alyousef L, Lahoud GA, Rousset SB, et al. (2009) [The role of biology in the diagnosis of cerebrospinal fluid leaks]. Ann Biol Clin (Paris) 67: 141-151

2. Domengie F, Cottier JP, Lescanne E, Aesch B, Vinikoff-Sonier C, et al. (2004) [Management of cerebrospinal fluid fistulae: physiopathology, imaging and treatment]. J Neuroradiol 31: 47-59.

3. Schmerber S, Boubagra K, Cuisnier O, Righini C, Reyt E (2001) [Methods of identification and localization of ethmoid and sphenoid osteomeningeal breaches]. Rev Laryngol Otol Rhinol (Bord) 122: 13-19.

4. Bell RB, Dierks EJ, Homer L, Potter BE (2004) Management of cerebrospinal fluid leak associated with craniomaxillofacial trauma. J Oral Maxillofac Surg 62: 676-684.

5. McMains KC, Gross CW, Kountakis SE (2004) Endoscopic management of cerebrospinal fluid rhinorrhea. Laryngoscope 114: 1833-1837.

6. Scholsem M, Scholtes F, Collignon F, Robe P, Dubuisson A, et al. (2008) Surgical management of anterior cranial base fractures with cerebrospinal fluid fistulae: a single-institution experience. Neurosurgery 62: 463-469.

7. Schlosser RJ, Bolger WE (2004) Nasal cerebrospinal fluid leaks: critical review and surgical considerations. Laryngoscope 114: 255-265.

8. Friedman JA, Ebersold MJ, Quast LM (2000) Persistent posttraumatic cerebrospinal fluid leakage. Neurosurg Focus 9: e1.

9. Eljamel MS (1994) Fractures of the middle third of the face and cerebrospinal fluid rhinorrhoea. Br J Neurosurg 8: 289-293.

10. Gendeh BS, Mazita A, Selladurai BM, Jegan T, Jeevanan J, et al. (2005) Endonasal endoscopic repair of anterior skull-base fistulas: the Kuala Lumpur experience. J Laryngol Otol 119: 866-874.

11. Raine C (2005) Diagnosis and management of otologic cerebrospinal fluid leak. Otolaryngol Clin North Am 38: 583-595, vii.

12. Tosun F, Gonul E, Yetiser S, Gerek M (2005) Analysis of different surgical approaches for the treatment of cerebrospinal fluid rhinorrhea. Minim Invasive Neurosurg 48: 355-360.

13. Righini C, Reyt E, Lavieille JP, Passagia JG, Charachon R (1996) [Surgical treatment under endoscopic control of cerebrospinal fluid rhinorrhea of sphenoid origin. A propos of 5 cases]. Ann Otolaryngol Chir Cervicofac 113: 188-195.

14. Schuknecht B, Simmen D, Briner HR, Holzmann D (2008) Nontraumatic skull base defects with spontaneous CSF rhinorrhea and arachnoid herniation: imaging findings and correlation with endoscopic sinus surgery in 27 patients. AJNR Am J Neuroradiol 29: 542-549.

15. Bachmann G, Elverland HH, Sørheim SI, Borota L (2003) [Diagnosis and surgical treatment of liquorrhea]. Tidsskr Nor Laegeforen 123: 3190-3192.

16. Eljamel MS, Foy PM (1990) Acute traumatic CSF fistulae: the risk of intracranial infection. Br J Neurosurg 4: 381-385.

17. Carrau RL, Snyderman CH, Kassam AB (2005) The management of cerebrospinal fluid leaks in patients at risk for high-pressure hydrocephalus. Laryngoscope 115: 205-212.

18. Daele JJ, Goffart Y, Machiels S (2011) Traumatic, iatrogenic, and spontaneous cerebrospinal fluid (CSF) leak: endoscopic repair. B-ENT 7 Suppl 17: 47-60. 